\title{
A Site-Selective Amination Catalyst Discriminates Between Nearly Identical C-H Bonds of Unsymmetrical Disubstituted Alkenes
}

Honghui Lei, Tomislav Rovis*

Department of Chemistry, Columbia University, New York, NY, USA.

$\mathrm{C}-\mathrm{H}$ activation reactions enable chemists to unveil new retrosynthetic disconnections and streamline conventional synthetic approaches. A longstanding challenge in $\mathrm{C}-\mathrm{H}$ activation is the inability to distinguish electronically and sterically similar $\mathrm{C}-\mathrm{H}$ bonds. Although numerous synergistic combinations of transition-metal complexes and chelating directing groups have been utilized to distinguish $\mathrm{C}-\mathrm{H}$ bonds, undirected regioselective $\mathrm{C}-\mathrm{H}$ functionalization strategies remain elusive. Herein, we report a regioselective $\mathrm{C}-\mathrm{H}$ activation/amination reaction of various unsymmetrical dialkyl-substituted alkenes. The regioselectivity of $\mathrm{C}-\mathrm{H}$ activation is correlated to the electronic properties of allylic $\mathrm{C}-\mathrm{H}$ bonds indicated by the corresponding ${ }^{1} \mathrm{~J}_{\mathrm{CH}}$ coupling constants. A linear relationship between the difference of ${ }^{1} \mathrm{~J}_{\mathrm{CH}}$ coupling constants of the two competing allylic $\mathrm{C}-\mathrm{H}$ bonds $\left(\Delta^{1} \mathrm{~J}_{\mathrm{CH}}\right)$ and the $\mathrm{C}-\mathrm{H}$ activation barriers $(\Delta$ $\left.\Delta \mathbf{G}^{\ddagger}\right)$ has also been determined.

The development of synthetic strategies to diversify molecular frameworks through site-selective functionalization of ubiquitous $\mathrm{C}-\mathrm{H}$ bonds has been an overarching goal in synthetic chemistry ${ }^{1,2,3,4}$. However, $\mathrm{C}-$ $\mathrm{H}$ bonds with nearly identical chemical environments give rise to an enormous challenge for achieving siteselectivity (Fig. 1a). The inherently difficult discrimination of these $\mathrm{C}-\mathrm{H}$ bonds has been achieved by the synergistic combination of transition-metal complexes and chelating directing groups ${ }^{5,6,7,8}$, which exploits the differences in conformational energies of the in-situ generated metallacycles in the transition state, so that a particular $\mathrm{C}-\mathrm{H}$ bond is favored. However, its synthetic applications are limited to substrates with preinstalled directing groups, which mandate additional synthetic steps for removal or further manipulation. A more direct and versatile approach may 
involve a catalyst system that recognizes the subtle differences in $\mathrm{C}-\mathrm{H}$ bond strengths, ultimately enabling a siteselective $\mathrm{C}-\mathrm{H}$ bond activation $9,10,11$. Electronic effects have been utilized as a powerful tool for the site-selective functionalization of arenes ${ }^{12,13,14}$. Nevertheless, the application of electronic factors in a broader context of $\mathrm{C}\left(\mathrm{sp}^{3}\right)-\mathrm{H}$ functionalizations is extremely challenging as the inductive effect gets weakened significantly through saturated bonds ${ }^{15,16,17}$.

Selective allylic $\mathrm{C}-\mathrm{H}$ functionalizations provide a platform for the construction of valuable building blocks from chemical feedstocks ${ }^{18,19,20,21,22}$. Currently, intermolecular allylic $\mathrm{C}-\mathrm{H}$ amination reactions are mostly limited to alkenes with only one distinct set of allylic protons ${ }^{23,24,25,26,27,28,29}$, due to the lack of methods to distinguish similar allylic positions. Two important exceptions are Dauban's work ${ }^{30}$ of $\mathrm{Rh}(\mathrm{II})$-catalyzed outer-sphere nitrene insertion preferring methylene over methyl $\mathrm{C}-\mathrm{H}$ bonds and Tambar's two-step protocol ${ }^{31}$ where an asymmetric ene-type transformation of cis-olefins was demonstrated to distinguish two allylic positions (Fig. 1b). However, selective $\mathrm{C}-\mathrm{H}$ activation/amination of alkenes possessing two similar sets of allylic protons has yet to be disclosed, presumably due to the following two issues: 1) two similar allylic $\mathrm{C}-\mathrm{H}$ bonds are competing for $\mathrm{C}-\mathrm{H}$ activation; and 2) two marginally distinguishable reactive sites of the resulting metal-allyl species could potentially lead to a mixture of four regioisomers, especially for substrates containing trans-1,2-disubstituted alkenes (Fig. 1c). Herein, we report a regioselective $\mathrm{C}-\mathrm{H}$ activation/amination reaction of unsymmetrical 1,1- and trans-1,2-disubstituted alkenes controlled. We further demonstrate that the exquisite selectivity is electronically controlled through the inherent inductive effect of a remote electron-withdrawing group. We propose that $\mathrm{C}-\mathrm{H}$ activation selectivity can be predicted using ${ }^{1} J_{\mathrm{CH}}$ coupling constants at the allylic positions, based on a linear relationship between $\Delta^{1} \mathrm{~J}_{\mathrm{CH}}$ coupling constant and selectivity. 
<smiles>[R]CCc1ccc(CC)cc1</smiles><smiles>[R]CCC(C)C(C)CCC([2H])C</smiles><smiles>[R]CCCC#CCCC</smiles><smiles>[R]c1ccc(CCC(C)c2ccc(C([2H])C)cc2)cc1</smiles>

b<smiles>CC(/C=C/C(C)CCO)CCO</smiles><smiles>CCC1CC1C</smiles><smiles>CC(/C=C/C(C)CCO)CCO</smiles>

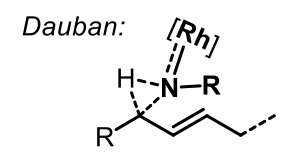

Outer-Sphere Nitrene Insertion

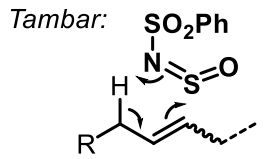
Ene-Type Reaction

C

This work:

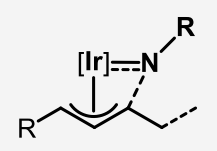

C-H Activation IAmination

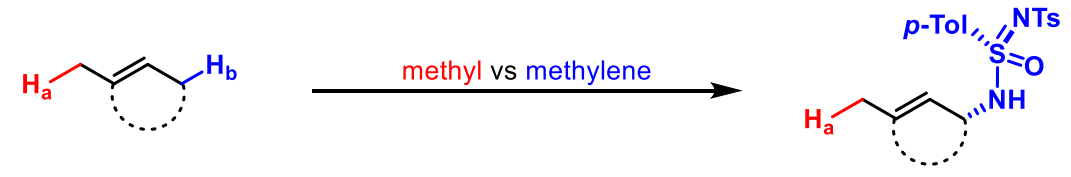

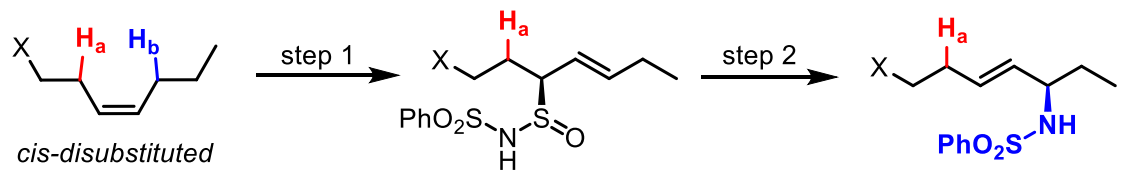

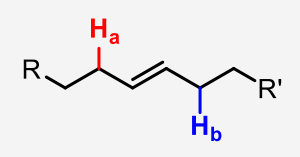

trans-disubstituted

or<smiles>[R]CC(C)C(=C)C(C)C[R]</smiles>

1,1-disubstituted

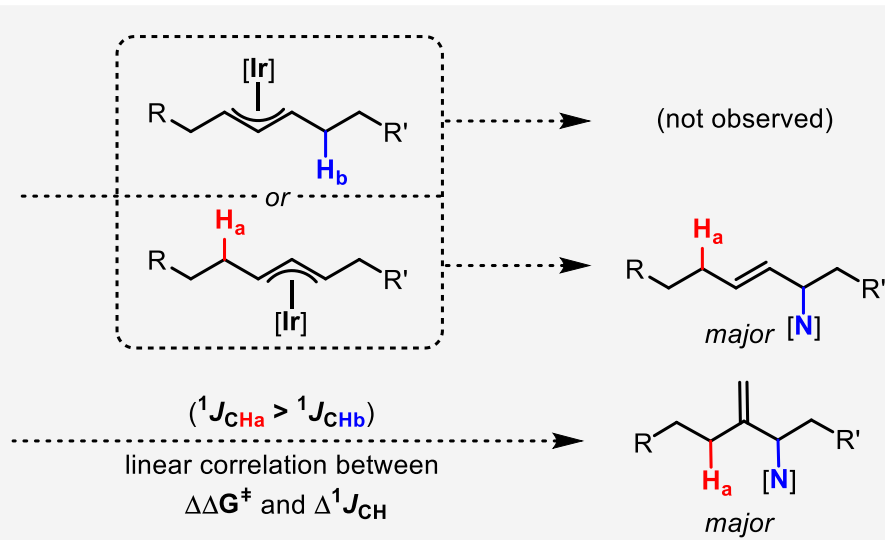

one of four possible isomers

Figure 1 Site-selective allylic $\mathbf{C}-\mathrm{H}$ amination. a, Distinguishing electronically and sterically similar $\mathrm{C}-\mathrm{H}$ bonds has been a

longstanding challenge. b. Previous examples of intermolecular regioselective allylic $\mathrm{C}-\mathrm{H}$ amination of alkenes possessing two sets of allylic protons. c, A summary of this work, illustrating successful regioselective $\mathrm{C}-\mathrm{H}$ activation and amination for $1,1-$ and trans-

1,2-disubstituted alkenes. [Ir], iridium complex; [N], nitrogen source.

\section{Results and discussion}

1,1-disubstituted alkene 1 a was selected as the model substrate to initiate our study. We postulated that the homoallylic trifluoromethyl group could electronically differentiate between potentially reactive $\beta$ and $\delta$ allylic $\mathrm{C}-\mathrm{H}$ bonds through the inductive effect. Following the selective $\mathrm{C}-\mathrm{H}$ activation, the resultant $\pi$-allyl-metal species may undergo selective $\mathrm{C}-\mathrm{N}$ bond formation at the internal position. At the outset, we first tested the reaction with 
$\left[\mathrm{Cp}^{*} \mathrm{MCl}_{2}\right]_{2}\left(\mathrm{M}=\mathrm{Co}, \mathrm{Rh}, \mathrm{Ir} ; \mathrm{Cp}^{*}=\right.$ pentamethylcyclopentadienyl $)$ as the precatalyst, silver tetrafluoroborate $\left(\mathrm{AgBF}_{4}\right)$ as the additive, lithium acetate ( $\mathrm{LiOAc})$ as the base, and $p$-toluenesulfonyl azide $\left(\mathrm{TsN}_{3}\right)$ as the nitrene precursor. Although no amination products were detected with either $\left[\mathrm{Cp}^{*} \mathrm{CoCl}_{2}\right]_{2}$ or $\left[\mathrm{Cp}^{*} \mathrm{RhCl}_{2}\right]_{2}$, we realized the formation of $\delta$ amination 2a as a major product with $\left[\mathrm{Cp}^{*} \mid \mathrm{ICl}_{2}\right]_{2}$ in moderate yield (Supplementary section 4). In line with our proposal, the reaction proceeds through the selective $\mathrm{C}-\mathrm{H}$ activation of the distal $\delta \mathrm{C}-\mathrm{H}$ bond, followed by $\mathrm{C}-\mathrm{N}$ bond formation at the internal position of the corresponding $\pi$-allyl-Ir species. After an extensive evaluation of the reaction conditions, the optimal conditions were achieved by making three crucial changes: 1) switching the ligand from $C p^{*}$ to $C p^{T M}\left(C p^{T M}=\right.$ tetramethylcyclopentadienyl), which significantly improves the yield; 2$)$ replacing lithium acetate with silver trifluoroacetate (AgTFA); 3) adding cesium carbonate $\left(\mathrm{Cs}_{2} \mathrm{CO}_{3}\right)$ as a co-base (Supplementary section 4). Control experiments further revealed that both $\left[\mathrm{Cp}^{\mathrm{TM}} \mid \mathrm{rCl}_{2}\right]_{2}$ and $\mathrm{AgBF}_{4}$ are necessary components for the reaction. Moreover, $\left[\mathrm{Cp}^{\mathrm{TM}} \operatorname{Ir}(\mathrm{TFA})_{2}\right]$ was also tested as a replacement for $\left.\left[\mathrm{Cp}^{*} \mid \mathrm{rCl}\right]_{2}\right]_{2}$ and $\mathrm{AgTFA}$, which leads to a comparable yield and regioselectivity, but no reactivity is observed in the absence of $\mathrm{AgBF}_{4}$. 


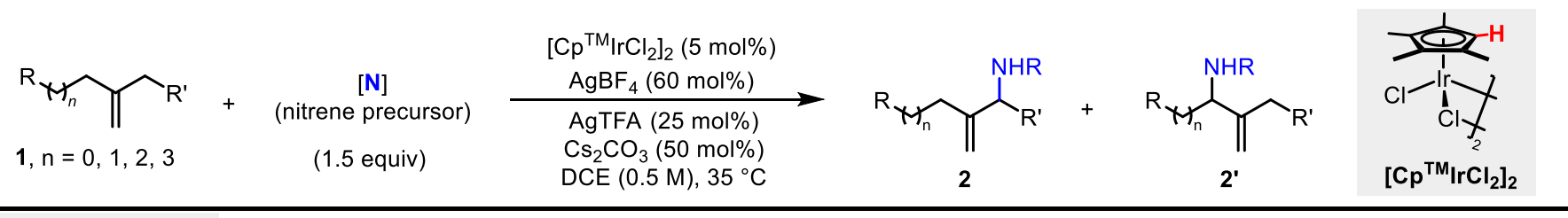

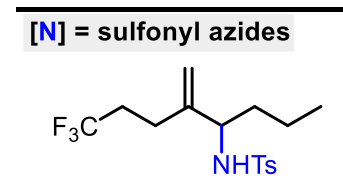

2a, $80 \%$, >20:1 rr<smiles>C=C(CCc1ccccc1)C(C)N</smiles>

2f, $78 \%, 11: 1^{b}$<smiles>C=C(CCCO)C(CC)CC[NH3+]</smiles>

2k, $71 \%, 12: 1$ rr $^{a, c}$<smiles>C=C(C)C([NH3+])CCO</smiles>

2p, $77 \%, 7.7: 1 \mathrm{rr}$<smiles>C=C(CCO[18OH])C([NH3+])CC</smiles>

2b, $73 \%$, >20:1 rr<smiles>C=C(CCc1ccc(C(F)(F)F)cc1)C(C)N</smiles>

2 g, $89 \%, 14: 1^{b}$

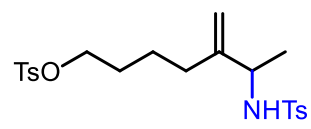

2I, $78 \%, 6.0: 1 \mathrm{rr}$<smiles>C=C(C)C(CCCOCCOCC)N[NH3+]</smiles>

2q, $87 \%,>20: 1$ rr<smiles>C=C(CCNc1ccccc1)C([NH3+])CC</smiles>

2c, $83 \%, 15: 1 \mathrm{rr}$<smiles>C=C(CCOCc1ccccc1)C(CC)N[Na]</smiles>

2d, $50 \%$, >20:1 rr

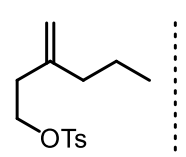

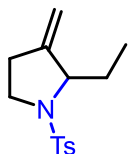

$2 e, 84 \%,>20: 1 r^{a}$<smiles>C=C(CCc1ccc(OC)c(OC)c1)C(C)N</smiles>

2h, $85 \%, 9.0: 1^{b}$<smiles>C=C(CNc1ccccc1)C(N)CCC</smiles>

$2 \mathbf{i}, 70 \%,>20: 1 \mathrm{rr}$<smiles>C=C(CCCC(F)(F)F)C([NH3+])CCC</smiles>

2j, $76 \%, 6.6: 1 \mathrm{rr}$

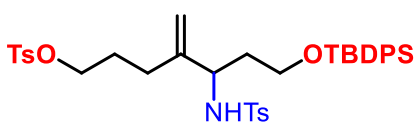

$2 \mathrm{~m}, 79 \%, 3.4: 1 \mathrm{rr}^{a}$<smiles>C=C(C)C(Cc1ccccc1)N[S+](=O)[O-]</smiles>

2n, $74 \%, 17: 1$ rr

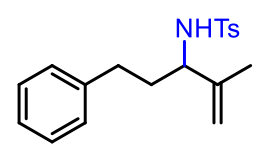

2o, $65 \%$, >20:1 rr<smiles>C=C(C)C([NH3+])CCC(C)CCOC(C)=O</smiles>

$2 \mathrm{r}, 77 \%,>20: 1 \mathrm{rr}, 1: 1 \mathrm{dr}^{d}$<smiles>C=C(CCC(F)(F)F)C(CCC)NS(=O)(=O)c1ccc([N+](=O)[O-])cc1</smiles>

$[\mathrm{N}]=$ dioxazolones<smiles>C/C=C(/CCC(F)(F)F)C(CCC)NC(C)=O</smiles>

$2 \mathbf{t}, 69 \%^{e}$ $>20: 1 \mathrm{rr}$ (C-H activation) 10:1 rr (amination)<smiles>C/C=C(/CCC(F)(F)F)C(CCC1CC1)NC(=O)C1CC1</smiles>

$2 \mathbf{u}, 64 \%^{\mathrm{e}, f}$ $>20: 1 \mathrm{rr}$ (C-H activation) 15:1 rr (amination)<smiles>C/C=C(/CCCC)C(CCC)NC(=O)P</smiles>

2v, $51 \%^{e}$ $>20: 1 \mathrm{rr}$ (C-H activation) 13:1 $\mathrm{rr}$ (amination)<smiles>C/C=C(/CCCF)[C@H](CCC)NC(=O)CF</smiles>

2w, $76 \%{ }^{e}$ $>20: 1 \mathrm{rr}$ (C-H activation) 18:1 rr (amination)<smiles>C/C=C(/CCC(F)(F)F)[C@H](CCC)NC(=O)C[NH2+]c1ccccc1</smiles>

$2 \mathbf{x}, 79 \%^{e}$

$>20: 1 \mathrm{rr}(\mathrm{C}-\mathrm{H}$ activation) $14: 1 \mathrm{rr}$ (amination)

Reactions were conducted on a $0.1 \mathrm{mmol}$ scale. Yields were determined after column chromatography. r.r. values were collected from ${ }^{1} \mathrm{H}$ NMR spectrum of unpurified reaction

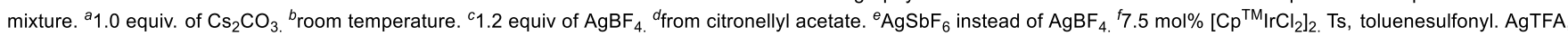
silver trifluoroacetate. TBDPS, tert-Butyldiphenylsilyl. PhthN, phthalimido.

Having established the optimal conditions, we investigated the scope of the reaction by examining a diverse array of unsymmetrical 1,1-dialkylsubstituted alkenes (Table 1). Various electron-withdrawing groups (EWG) are tolerated providing excellent yields and regioselectivities (2a-2e). Notably, when a suitably placed toluenesulfonate group (OTs) is present, a pyrrolidine ring is formed in situ from the corresponding amination product (2e). High selectivity is also observed with a weakly electron-withdrawing phenyl group, and the electron density of the arene affects the regioselectivity $(\mathbf{2 f - 2} \mathbf{h})$. With respect to the distance between the EWG and olefin, this method tolerates 
tethers ranging from one to four methylene units while maintaining good reactivity and regioselectivity (2i-2I).

Surprisingly, substrates bearing marginally different allylic $\mathrm{C}-\mathrm{H}$ bonds, which are remotely influenced by OTs vs

OTBDPS, react with measurable selectivity $(\mathbf{2 m})$. Moreover, the reaction is exquisitely selective for secondary $\mathrm{C}-\mathrm{H}$ bonds over methyl groups under the standard conditions, and the regioselectivity increases as the EWG moves away from the reactive center (2n-2q). In terms of trisubstituted olefins, citronellyl acetate provides the allylic amine with migration of the double bond to the terminal position (2r). $p$-Nitrobenzene-sulfonyl azide can also be employed, which allows facile deprotection (2s). Besides sulfonyl azides, a variety of dioxazolones were utilized under slightly modified conditions. Various amides, possessing substitutions that include phenyl, cyclopropyl, $\alpha-$ fluoro, or a-amino groups are effectively incorporated in the distal allylic position (2t-2x).

Table $2 \mathrm{Cp}$ ligand study and scope of unsymmetrical trans-1,2-disubstituted alkenes

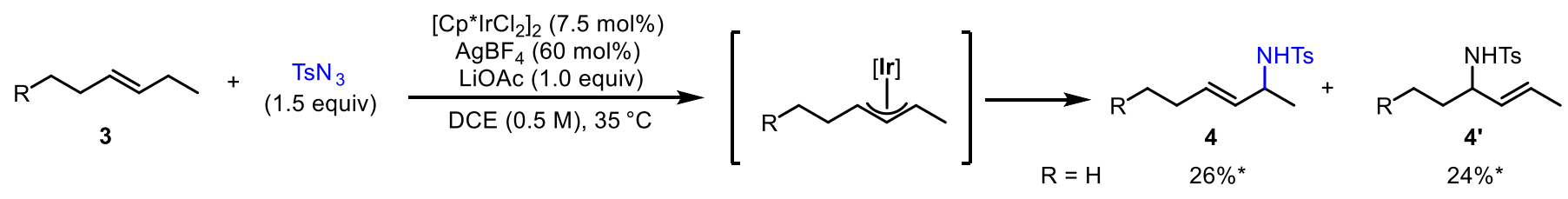

Cp ligand study with $3 a$ :

3a, $\mathrm{R}=\mathrm{OTs} \quad 62 \%$ *

$10 \%$ *

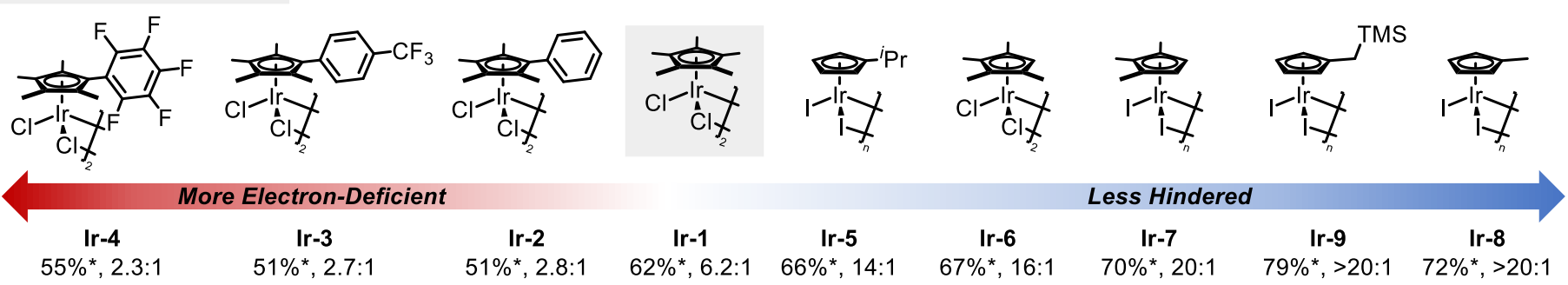

Trans-1,2-alkene scope with Ir-9 (15 mol\% of Ir-mononer):

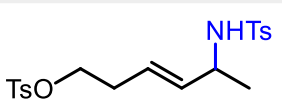

4a, $76 \%,>20: 1$<smiles>CC([NH3+])/C=C/CNP</smiles>

4f, $83 \%,>20: 1 \mathrm{rr}^{a}$

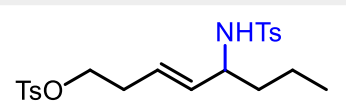

4b, $73 \%,>20: 1$

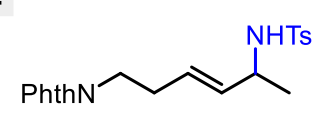

4c, $70 \%, 15: 1$

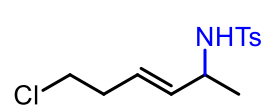

$4 d, 44 \%, 8.0: 1$

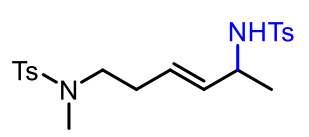

$4 e, 50 \%, 6.5: 1$<smiles>CCC([15NH])/C=C/C(=O)O</smiles>

4h, $86 \%,>20: 1 \mathrm{rr}^{a b}$<smiles>CCCC(N)/C=C/C(=O)OCC</smiles>

$4 \mathbf{i}, 93 \%,>20: 1 \mathrm{rr}^{\mathrm{ab}}$

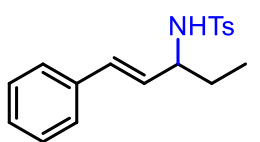

4j, $71 \%,>20: 1$

Reactions were conducted on a $0.1 \mathrm{mmol}$ scale. Yields were determined after column chromatography. Yields ${ }^{*}$ and r.r. values were collected from ${ }^{1} \mathrm{H}$ NMR spectrum of unpurified reaction mixutre with mesitylene as the internal standard. ${ }^{a} 5 \mathrm{~mol} \%\left[\mathrm{Cp}^{\mathrm{TM}} \mathrm{IrCl}_{2}\right]_{2}$ (Ir-6) was used. ${ }^{b}$ Reaction was conducted at $50{ }^{\circ} \mathrm{C}$.

Based on the success of selective $\mathrm{C}-\mathrm{H}$ activation of 1,1-disubstituted alkenes, we envisioned that similar selectivity could also be achieved with unsymmetrical trans-1,2-disubstituted alkenes containing a remote 
electron-withdrawing group (EWG). However, the $\pi$-allyl-metal intermediates derived from $\mathrm{C}-\mathrm{H}$ activation of $1,2-$ dialkylsubstituted alkenes bearing two similar internal positions have rarely been differentiated ${ }^{32}$. We speculated that the electronic difference between the two reactive sites, produced by the inductive effect, could also lead to regioselective nitrene insertion. To set the stage, we examined the Ir-catalyzed $\mathrm{C}-\mathrm{H}$ activation/amination of trans3-hexene, a symmetrical substrate that would lead to an unsymmetrical $\pi$-allyl-Ir intermediate. In the event, under standard reaction conditions, amination occurs unselectively to give two products (Table 2). In contrast, reaction of substrate $3 a$ bearing $p$-toluenesulfonate (OTs) as the EWG leads to a moderate selectivity favoring the more electron-rich side of the $\pi$-allyl-Ir intermediate, which results from $\mathrm{C}-\mathrm{H}$ activation of the distal allylic $\mathrm{C}-\mathrm{H}$ bond. Regioisomers derived from $\mathrm{C}-\mathrm{H}$ activation of the proximal $\mathrm{C}-\mathrm{H}$ bonds were not detected. The electronic effect of the $\mathrm{Cp}$ ligand $\mathrm{d}^{33,34}$ was investigated by comparing catalysts Ir-2, Ir-3, and Ir-4, bearing electronically variant aryl rings on the $\mathrm{Cp}$ core. These catalysts all lead to inferior regioselectivities, suggesting that the electron density of the $\mathrm{Cp}$ ligand has little effect on the regioselectivity while the steric properties seem to have a profound influence. Indeed, when the Cp ligand contains fewer methyl groups, the regioselectivity is dramatically improved (Ir-6, Ir-7, and Ir-8). Additionally, by comparing the outcomes of Ir-5 and Ir-8, both mono-alkyl Cp derivatives, the same steric effect on the regioselectivity is observed. Eventually, an electron-donating hyperconjugative interaction was found to improve the productive reactivity, which delivers Ir-9 as the optimal catalyst ${ }^{35}$.

The scope of trans-1,2-disubstituted alkenes was then explored. Substrate $\mathbf{3 b}$ bearing an $n$-butyl group is tolerated, indicating that the regioselectivity is not related to the steric bias between two sides of the $\pi$-allyl-Ir intermediate. Other electron-withdrawing groups may be used, including one with chloride substitution (4c-4e). Allylic substitutions that are known to deactivate the alkene also perform well $(\mathbf{4 f}, \mathbf{4 g})$. Even those substrates with conjugated carbonyl groups are reactive at elevated temperature, leading to the desired amination products (4h, 4i). Additionally, $\beta$-alkyl styrene $\mathbf{3 j}$ was found to give the conjugated amination product $\mathbf{4} \mathbf{j}$ selectively, which is complementary to Blakey’s report using $\mathrm{Cp}^{*} \mathrm{Rh}$-catalyst and tert-butyldioxazolone ${ }^{29}$. 


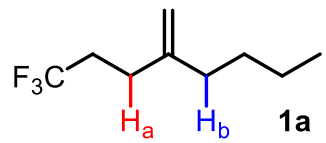

${ }^{1} \mathrm{~J}_{\mathrm{CH}}$ Coupling Constant: $\left.\begin{array}{l}{ }^{1} \mathrm{~J}_{\mathrm{CHa}}=127.0 \mathrm{~Hz} \\ { }^{1} \mathrm{~J}_{\mathrm{CHb}}=124.4 \mathrm{~Hz}\end{array}\right\} \Delta=\mathbf{2 . 6}$

Regioselectivity:

$1: 35$

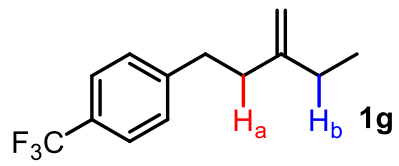

${ }^{1} J_{\mathrm{CH}}$ Coupling Constant: $\left.\begin{array}{l}{ }^{1} J_{\mathrm{CHa}}=126.5 \mathrm{~Hz} \\ { }^{1} J_{\mathrm{CHb}}=124.9 \mathrm{~Hz}\end{array}\right\} \Delta=\mathbf{1 . 6}$

Regioselectivity:

$1: 14$

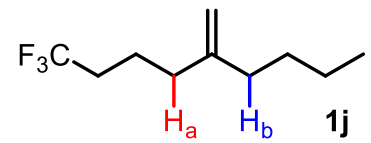

$\left.\begin{array}{l}{ }^{1} J_{\mathrm{CHa}}=125.4 \mathrm{~Hz} \\ { }^{1} J_{\mathrm{CHb}}=124.5 \mathrm{~Hz}\end{array}\right\} \Delta=\mathbf{0 . 9}$

$1: 6.6$

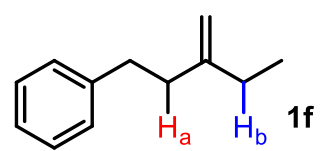

$\left.\begin{array}{l}{ }^{1} J_{\mathrm{CHa}}=126.2 \mathrm{~Hz} \\ { }^{1} J_{\mathrm{CHb}}=124.8 \mathrm{~Hz}\end{array}\right\} \Delta=1.4$

$1: 11$

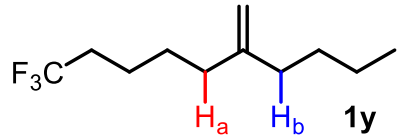

$\left.\begin{array}{l}{ }^{1} J_{\mathrm{CHa}}=124.6 \mathrm{~Hz} \\ { }^{1} J_{\mathrm{CHb}}=124.4 \mathrm{~Hz}\end{array}\right\} \Delta=\mathbf{0 . 2}$

$1: 2.0$

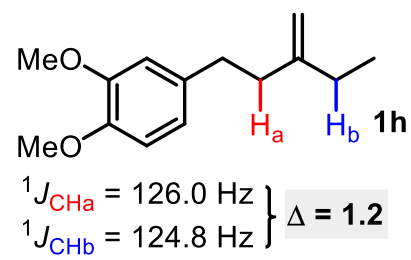

$1: 9.0$

b

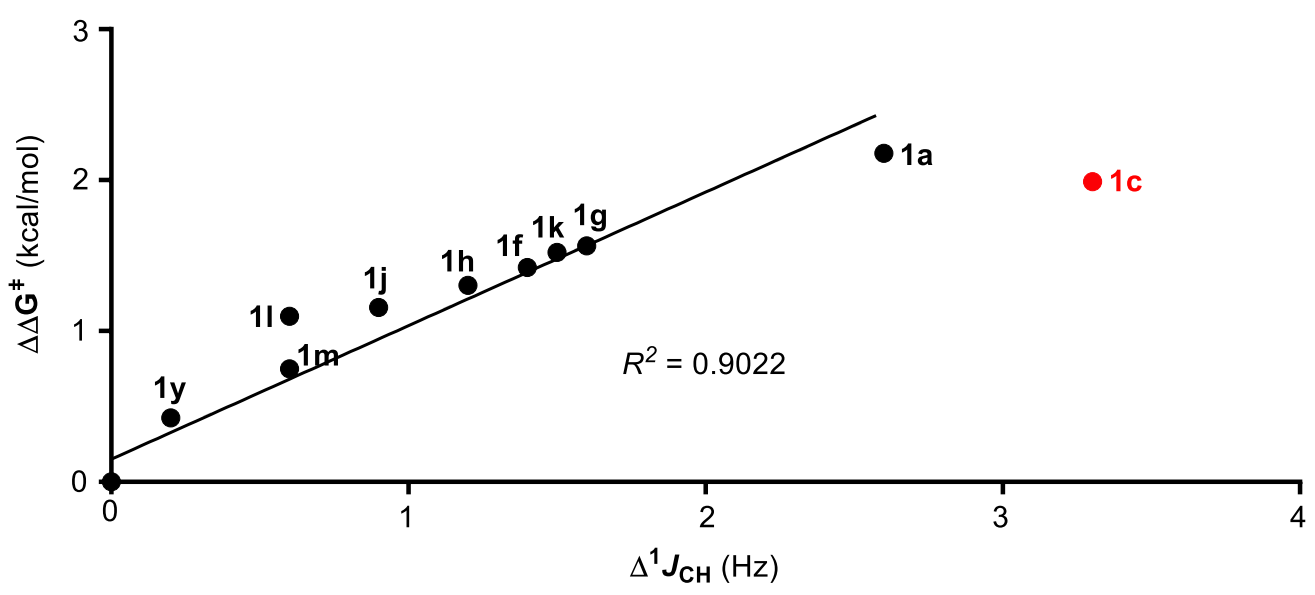

Figure 2 Study of the origin of regioselectivities. a, Inductive effect induced changes in ${ }^{1} J_{C H}$ coupling constants and regioselectivities . b, A linear relationship between $\Delta^{1} J_{C H}$ and $\Delta \Delta G^{\ddagger}$.

To gain further insight into the origin of the observed regioselectivities, we conducted several studies probing the mechanism and the impact of substrate electronics. Several experiments proved particularly enlightening. On the basis of a deuterium labeling experiments, we conclude that the allylic $\mathrm{C}-\mathrm{H}$ activation step is irreversible for both alkene classes (Supplementary section 7). ${ }^{1} \mathrm{~J}_{\mathrm{CH}}$ coupling constants ${ }^{36}$, which are closely correlated with the $s$ character of the $\mathrm{C}-\mathrm{H}$ bonding orbital and also influenced by the nature of substituents, were utilized to understand the electronic properties of allylic $\mathrm{C}-\mathrm{H}$ bonds (Fig. 2a). Comparing the data of substrates, $\mathbf{1 a}, \mathbf{1 j}$, and $\mathbf{1 y}$, we noticed that the $\Delta{ }^{1} \mathrm{~J}_{\mathrm{CH}}$ coupling constant between two sides of the olefin decreases as the $\mathrm{CF}_{3}$ group becomes more distal to the double bond. As the electron density of the aromatic ring two methylenes away from the alkene is varied, regioselectivity also varies and correlates to the change in the $\Delta^{1} \mathrm{~J}_{\mathrm{CH}}$ coupling constant between two 
sides of the olefin. Indeed, we graphed the results for ten substrates chosen from Table $1,{ }^{37}$ and find a linear relationship between $\Delta^{1} J_{C H}$ coupling constant and the difference of $\mathrm{C}-\mathrm{H}$ activation barriers $\left(\Delta \Delta \mathrm{G}^{\ddagger}\right)$ (Fig. $\left.2 \mathrm{~b}\right)$. The sole outlier (1c) also has a Lewis basic carbonyl which could engage the Ir. These results are consistent with our hypothesis that the electronic difference between allylic $\mathrm{C}-\mathrm{H}$ bonds, which is introduced by the inductive effect, is the primary factor contributed to the regioselectivity.

Table 3 Intermolecular competition reactions

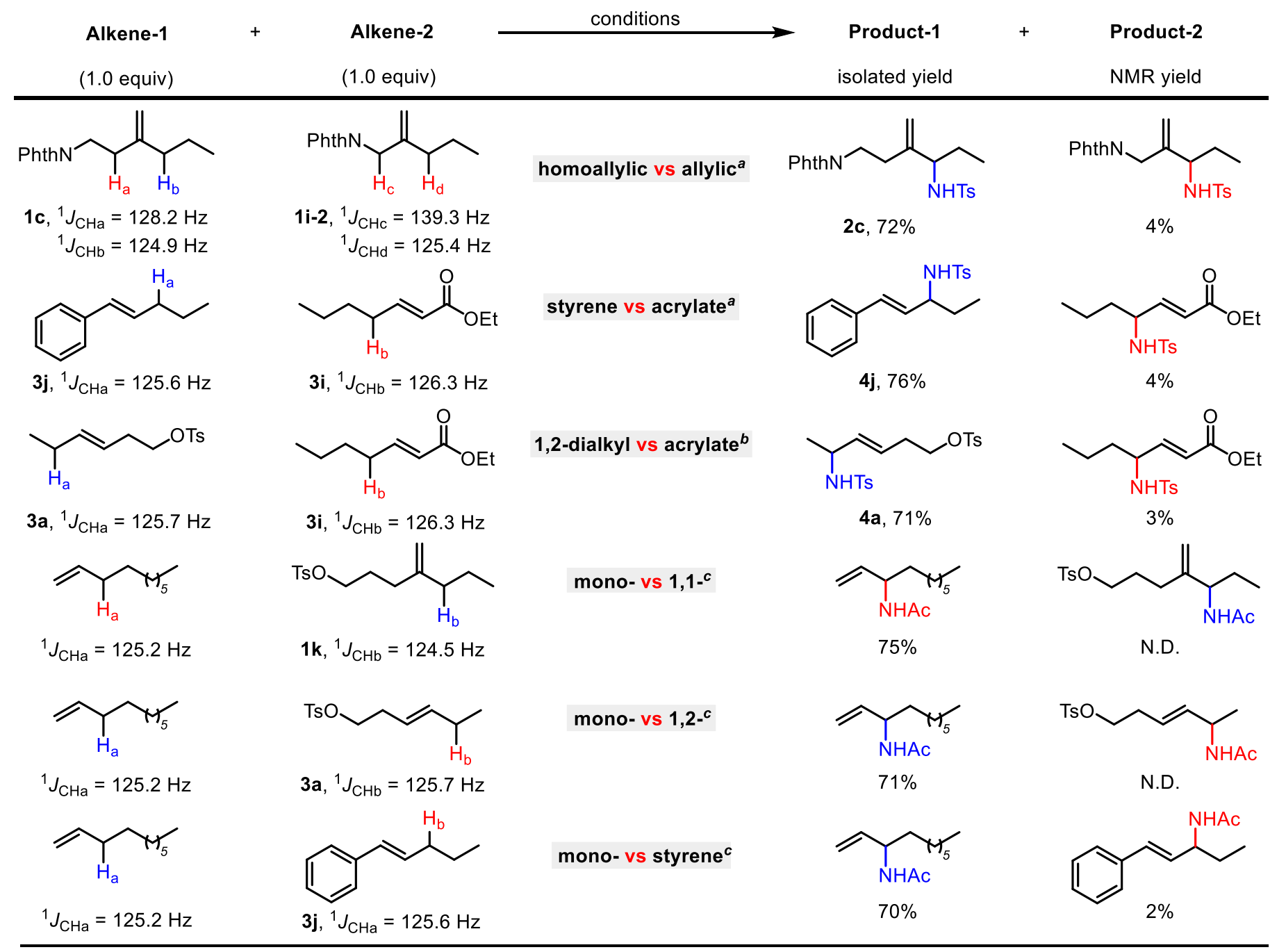

All the intermolecular competition reactions were conducted with 1:1 ratio of two alkenes. ${ }^{a} \mathbf{I r}-6(5.0 \mathrm{~mol} \%), \mathrm{AgBF}_{4}\left(60 \mathrm{~mol}^{2}\right), \mathrm{AgTFA}(25 \mathrm{~mol} \%), \mathrm{Cs}_{2} \mathrm{CO}_{3}\left(50 \mathrm{~mol}^{2}\right)$,

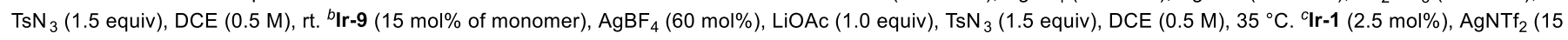
$\mathrm{mol} \%)$, LiOAc $(20 \mathrm{~mol} \%)$, methyldioxazolone (1.5 equiv), DCE $(0.5 \mathrm{M}), 35^{\circ} \mathrm{C}$.

Besides the selectivities between two sets of allylic $\mathrm{C}-\mathrm{H}$ bonds or two positions of the $\pi$-allyl-Ir intermediates, intermolecular competition reactions were studied (Table 3). For example, a competition reaction between 1:1 ratio of substrates $1 \mathrm{c}$ and $1 \mathrm{i}-2$ produces $2 \mathrm{c}$ as the major product, which suggests the preference of the allylic $\mathrm{C}-\mathrm{H}$ 
bonds with the smallest ${ }^{1} J_{\mathrm{CH}}$ coupling constant among total four sets of allylic protons. Moreover, $\beta$-alkyl styrene 3j and 1,2-trans-alkene 3a are more reactive than $\alpha, \beta$-unsaturated ester $\mathbf{3 i}$ because of the electronic deactivation by the conjugated carbonyl group $\left({ }^{1} \mathrm{~J}_{\mathrm{CHa}}<{ }^{1} \mathrm{~J}_{\mathrm{CHb}}\right)$. Additionally, accessibility of the alkene plays an important role in the intermolecular competition reactions. For instance, 1-decene undergoes allylic amination completely selectively over either 1,1- or 1,2-disubstituted alkenes, regardless of the electronic properties of the allylic $\mathrm{C}-\mathrm{H}$ bonds.

\section{Conclusion}

In summary, we have developed an intermolecular regioselective allylic $\mathrm{C}-\mathrm{H}$ amination of unsymmetrical disubstituted alkenes. This method exploits subtle electronic differences induced by remote electron withdrawing groups to effect a selective $\mathrm{C}-\mathrm{H}$ activation of allylic $\mathrm{C}-\mathrm{H}$ bonds. The selectivity can be predicted based on the linear relationship between the $\Delta^{1} J_{C H}$ coupling constants of two competing $\mathrm{C}-\mathrm{H}$ bonds and the difference of $\mathrm{C}-\mathrm{H}$ activation barriers $\left(\Delta \Delta G^{\ddagger}\right)$. The key findings also include the successful differentiation of two internal positions of the $\pi$-allyl-Ir intermediates with the assistance of the novel monosubstituted $\mathrm{Cp}$ ligand. We further provide a rubric by which to understand $\mathrm{C}-\mathrm{H}$ activation in more complex systems resulting from competition experiments. More broadly, we envision that this protocol could also benefit other allylic $\mathrm{C}-\mathrm{H}$ functionalizations of unsymmetrical internal olefins.

\section{Methods}

\section{General procedure for 1,1-disubstituted alkenes with $\mathrm{TsN}_{3}$}

To an oven-dried screw-capped vial with a magnetic stir bar was sequentially added alkene (0.1 mmol, 1.0 equiv), tosyl azide (23 $\mu \mathrm{l}, 1.5$ equiv), [ $\left.\mathrm{Cp}^{\mathrm{TM}} \mathrm{IrCl}_{2}\right]_{2}$ (Ir-6) (3.9 mg, $5.0 \mathrm{~mol} \%$ ), cesium carbonate (16.3 mg, $50 \mathrm{~mol} \%$ ), silver trifluoroacetate (5.5 mg, $25 \mathrm{~mol} \%)$, silver tetrafluoroborate $(11.7 \mathrm{mg}, 60 \mathrm{~mol} \%)$, and 1,2-dichloroethane (200 $\mu$, 
$0.5 \mathrm{M})$. The cap was screwed on, and the reaction was stirred at $35^{\circ} \mathrm{C}$ for 20 hours. The reaction mixture was filtered through a plug of Celite, and the filtrate was concentrated under vacuum. The crude mixture was analyzed via ${ }^{1} \mathrm{H}$ NMR spectroscopy with mesitylene $(12.0 \mathrm{mg}, 0.1 \mathrm{mmol})$ as an internal standard. The sample was further purified by column chromatography to give the desired amination product.

\section{General procedure for 1,2-disubstituted alkenes}

To an oven-dried screw-capped vial with a magnetic stir bar was sequentially added Ir-9 $(9.0 \mathrm{mg}, 15 \mathrm{~mol} \%$ of monomer), lithium acetate (6.6 mg, 1.0 equiv), and silver tetrafluoroborate (11.7 mg, $60 \mathrm{~mol} \%)$. In a separated vial alkene ( $0.1 \mathrm{mmol}, 1.0$ equiv) and tosyl azide ( $23 \mu \mathrm{l}, 1.5$ equiv) were dissolved in 1,2-dichloroethane (200 $\mu \mathrm{l}, 0.5$ $M)$, and the resultant solution was transferred to the first vial. The cap was screwed on, and the reaction was stirred at $35{ }^{\circ} \mathrm{C}$ for 40 hours. The reaction mixture was filtered through a plug of Celite, and the filtrate was concentrated under vacuum. The crude mixture was analyzed via ${ }^{1} \mathrm{H}$ NMR spectroscopy with mesitylene $(12.0 \mathrm{mg}$, $0.1 \mathrm{mmol}$ ) as an internal standard. The sample was further purified by column chromatography to give the desired amination product.

\section{Data availability}

All data that support the findings of this study are available in the Article and its Supplementary Information.

\section{References}

${ }^{1}$ McMurray, L., O’Hara, F. \& Gaunt, M. J. Recent developments in natural product synthesis using metalcatalysed C-H bond functionalisation. Chem. Soc. Rev. 40, 1885-1898 (2011).

2 Gutekunst, W. R. \& Baran, P. S. C-H functionalization logic in total synthesis. Chem. Soc. Rev. 40, 1976-1991 (2011).

3 Yamaguchi, J., Yamaguchi, A. D. \& Itami, K. C-H bond functionalization: emerging synthetic tools for natural products and pharmaceuticals. Angew. Chem. Int. Ed. 51, 8960-9009 (2012). 
${ }^{4}$ Cernak, T., Dykstra, K. D., Tyagarajan, S., Vachal, P. \& Krska, S. W. The medicinal chemist's toolbox for late stage functionalization of drug-like molecules. Chem. Soc. Rev. 45, 546-576 (2016).

${ }^{5}$ Colby, D. A., Bergman, R. G. \& Ellman, J. A. Rhodium-catalyzed C-C bond formation via heteroatom-directed C-H bond activation. Chem. Rev. 110, 624-655 (2010).

${ }^{6}$ Lyons, T. W. \& Sanford, M. S. Palladium-catalyzed ligand-directed C-H functionalization reactions. Chem. Rev. 110, 1147-1169 (2010).

7 He, J., Wasa, M., Chan, K. S. L., Shao, Q. \& Yu, J.-Q. Palladium-catalyzed transformations of alkyl C-H bonds. Chem. Rev. 117, 8754-8786 (2017).

${ }^{8}$ Sambiagio, C., Schönbauer, D., Blieck, R., Dao-Huy, T., Pototschnig, G., Schaaf, P., Wiesinger, T., Zia, M. F., WencelDelord, J., Besset, T., Maes, B. U. W. \& Schnürch, M. A comprehensive overview of directing groups applied in metal-catalysed C-H functionalisation chemistry. Chem. Soc. Rev. 47, 6603-6743 (2018).

${ }^{9}$ Newhouse, T. \& Baran, P. S. If C-H bonds could talk: selective $\mathrm{C}-\mathrm{H}$ bond oxidation. Angew. Chem. Int. Ed. 50, 3362-3374 (2011).

10 Hartwig, J. F. \& Larsen, M. A. Undirected, homogeneous C-H bond functionalization: challenges and opportunities. ACS Cent. Sci. 2, 281-292 (2016).

11 Xue, X.-S., Ji, P., Zhou, B. \& Cheng, J.-P. The essential role of bond energetics in C-H activation/functionalization. Chem. Rev. 117, 8622-8648 (2017).

12 Romero, N. A., Margrey, K. A., Tay, N. E. \& Nicewicz, D. A. Site-selective arene C-H amination via photoredox catalysis. Science $\mathbf{3 4 9}, 1326-1330$ (2015).

13 Paudyal, M. P., Adebesin, A. M., Burt, S. R., Ess, D. H., Ma, Z., Kürti, L. \& Falck, J. R. Dirhodium-catalyzed C-H arene amination using hydroxylamines. Science 353, 1144-1147 (2016).

14 Berger, F., Plutschack, M. B., Riegger, J., Yu, W., Speicher, S., Ho, M., Frank, N. \& Ritter, T. Site-selective and versatile aromatic C-H functionalization by thianthrenation. Nature 567, 223-228 (2019).

${ }^{15}$ Chen, M. S. \& White, M. C. Combined effects on selectivity in Fe-catalyzed methylene oxidation. Science 327, 566-571 (2010).

${ }^{16}$ Schmidt, V. A., Quinn, R. K., Bruscoe, A. T. \& Alexanian, E. J. Site-selective aliphatic C-H bromination using N-bromoamides and visible light. J. Am. Chem. Soc. 136, 14389-14392 (2014).

17 Sharma, A. \& Hartwig, J. H. Metal-catalysed azidation of tertiary C-H bonds suitable for late-stage functionalization. Nature 517, 600-604 (2015).

18 Eames, J. \& Watkinson, M. Catalytic allylic oxidation of alkenes using an asymmetric Kharasch-Sosnovsky 
reaction. Angew. Chem. Int. Ed. 40, 3567-3571 (2001).

19 Sharma, A. \& Hartwig, J. F. Enantioselective functionalization of allylic C-H bonds following a strategy of functionalization and diversification. J. Am. Chem. Soc. 135, 17983-17989 (2013).

${ }^{20}$ Cuthbertson, J. D. \& MacMillan, D. W. C. The direct arylation of allylic sp3 C-H bonds via organic and photoredox catalysis. Nature 519, 74-77 (2015).

${ }^{21}$ Liu, W., Ali, S. Z., Ammann, S. E. \& White, M. C. Asymmetric allylic C-H alkylation via palladium(II)/cis-ArSOX catalysis. J. Am. Chem. Soc. 140, 10658-10662 (2018).

${ }^{22}$ Li, J., Zhang, Z., Wu, L., Zhang, W., Chen, P., Lin, Z. \& Liu G. Site-specific allylic C-H bond functionalization with a copper-bound N-centred radical. Nature 574, 516-521 (2019).

${ }^{23}$ Reed, S. A. \& White, M. C. Catalytic intermolecular linear allylic C-H amination via heterobimetallic catalysis. J. Am. Chem. Soc. 130, 3316-3318 (2008).

${ }^{24}$ Liu, G., Yin, G. \& Wu, L. Palladium-catalyzed intermolecular aerobic oxidative amination of terminal alkenes: efficient synthesis of linear allylamine derivatives. Angew. Chem., Int. Ed. 47, 4733-4736 (2008).

${ }^{25}$ Bao, H. \& Tambar, U. K. Catalytic enantioselective allylic amination of unactivated terminal olefins via an ene reaction/[2,3]-rearrangement. J. Am. Chem. Soc. 134, 18495-18498 (2012).

${ }^{26}$ Burman, J. S. \& Blakey, S. B. Regioselective intermolecular allylic C-H amination of disubstituted olefins via rhodium/m-allyl intermediates. Angew. Chem., Int. Ed. 56, 13666-13669 (2017).

27 Lei H. \& Rovis, T. Ir-catalyzed intermolecular branch-selective allylic C-H amidation of unactivated terminal olefins. J. Am. Chem. Soc. 141, 2268-2273 (2019).

${ }^{28}$ Knecht, T., Mondal, S., Ye, J. H., Das, M. \& Glorius, F. Intermolecular, branch-selective, and redox-neutral Cp*Ir'II-catalyzed allylic C-H amidation. Angew. Chem., Int. Ed. 58, 7117-7121 (2019).

${ }^{29}$ Burman, J. S., Harris, R. J., Farr, C. M. B., Bacsa, J. \& Blakey, S. B. Rh(III) and Ir(III)Cp* complexes provide complementary regioselectivity profiles in intermolecular allylic $\mathrm{C}-\mathrm{H}$ amidation reactions. ACS Catal. 9, 54745479 (2019).

30 Liang, C., Collet, F., Robert-Peillard, F., Müeller, P., Dodd, R. H. \& Dauban, P. Toward a synthetically useful stereoselective C-H amination of hydrocarbons. J. Am. Chem. Soc. 130, 343-350 (2008).

${ }^{31}$ Bayeh, L., Le, P. Q. \& Tambar, U. K. Catalytic allylic oxidation of internal alkenes to a multifunctional chiral building block. Nature 547, 196-200 (2017).

32 Szabó, K. J. Nature of the interaction between $\beta$-substituents and the allyl moiety in ( $\eta 3$-allyl)palladium complexes. Chem. Soc. Rev. 30, 136-143 (2001). 
33 Piou, T., Romanov-Michailidis, F., Romanova-Michaelides, M., Jackson, K. E., Semakul, N., Taggart, T. D., Newell, B. S., Rithner, C. D., Paton, R. S. \& Rovis, T. Correlating reactivity and selectivity to cyclopentadienyl ligand properties in $\mathrm{Rh}(\mathrm{III})$-catalyzed $\mathrm{C}-\mathrm{H}$ activation reactions: an experimental and computational study. J. Am. Chem. Soc. 139, 1296-1310 (2017).

${ }^{34}$ Piou, T. \& Rovis, T. Electronic and Steric Tuning of a Prototypical Piano Stool Complex: Rh(III) Catalysis for C-H Functionalization. Acc. Chem. Res. 51, 170-180 (2018).

35 In general, Ir-8 leads to lower yields than Ir-9. For example, $54 \%$ yield of $\mathbf{4 c}$ and $35 \%$ yield of $\mathbf{4 d}$ were obtained with Ir-8.

${ }^{36}$ Hansen, P. E. Carbon-hydrogen spin-spin coupling constants. Prog. Nucl. Magn. Reson. Spectrosc. 14, 175295 (1981).

${ }^{37}$ All substrates involving a methylene vs methylene competition from Table 1 were chosen except those where accurate selectivity was difficult to determine accurately (>20:1 rr).

\section{Acknowledgements}

We thank NIGMS (GM80442) for support. We thank John Decatur (Columbia University) for assistance with determining ${ }^{1} \mathrm{~J}_{\mathrm{CH}}$ coupling constants.

\section{Author contributions}

$\mathrm{HL}$ and TR conceived and initiated the study. $\mathrm{HL}$ designed and conducted the experiments. HL and TR co-wrote the manuscript.

\section{Competing interests}

The authors declare no competing interests. 